\title{
PERSPECTIVE
}

\section{The A, B, Gs of silencing}

\author{
Edwin Smith and Ali Shilatifard ${ }^{1}$ \\ Stowers Institute for Medical Research, Kansas City, Missouri 64110, USA
}

Transcriptional silencing of mammalian genes is mediated by at least two modes of methylation: (1) cytosine methylation of DNA, and (2) methylation of the histones tails-both of which play an important role in transcriptional silencing from chromosomal DNA. Although there is some evidence that these pathways are interdependent, experimentally, they have largely been treated as two distinct processes. In this issue of Genes \& Development, Smallwood et al. (2007) have taken a pioneering step toward defining the molecular mechanism by which these two types of methylations can cooperate to silence a euchromatic gene, and demonstrate that the DNA methyltransferase 1 (DNMT1) cytosine methyltransferase physically and functionally interacts with three Heterochromatin Protein 1 (HP1) family members $(\alpha, \beta$, and $\gamma)$ to implement gene silencing.

DNA methylation is required for normal development in mammals. It is brought about by the de novo methyltransferases DNMT3a and DNMT3b and is propagated by the maintenance methyltransferase DNMT1 (for review, see Goll and Bestor 2005). DNA methylation is associated with silencing repetitive elements in the genome, X-chromosome inactivation in female mammals, and silencing of individual genes during development (for review, see Li and Bird 2007). Furthermore, DNA methylation is misregulated in cancer cells such that tumor suppressor genes are silenced to favor the growth of the tumor while repetitive regions of the genome are desilenced, which can contribute to genomic instability (for review, see Baylin and Jones 2007). However, the exact molecular mechanism of DNA methylation in transcriptional regulation and during the pathogenesis of cancer remains unclear.

The core histone proteins are wrapped by 147 base pairs of DNA forming the intact nucleosome. The histone $\mathrm{N}$ termini, or tails, extend away from the core of the nucleosome and are available for interactions with the DNA, histone-modifying enzymes, and other proteins, which alter the nucleosome structure (Shilatifard 2006). There are multiple modification sites on each histone tail, and some amino acids in the histone tail can be modified in two or more ways. Histone methylation at Lys 9 of H3 is associated with silencing at both heterochromatin and euchromatic sequences in a variety of

${ }^{1}$ Corrresponding author.

E-MAIL ASH@Stowers-Institute.org; FAX (816) 926-4112.

Article is online at http://www.genesdev.org/cgi/doi/10.1101/gad.1559407. systems (for review, see Ebert et al. 2006; Shilatifard 2006). Recent evidence demonstrates that it is also associated with transcribed regions of euchromatic genes, indicating that this modification can have distinct meanings in different contexts (Vakoc et al. 2005; Eissenberg and Shilatifard 2006).

Not only can the lysine residues within histones be modified by methylation, this modification can occur in three different states. Lysine residues can accept up to three methyl groups and therefore be mono-, di-, or trimethylated. For H3K9, the pattern of mono-, di-, and trimethylation is mediated by the catalytic properties of different enzymes. For example, the G9a methyltransferase mediates dimethylation of $\mathrm{H} 3 \mathrm{~K} 9$ and is associated with silencing of euchromatic genes (Tachibana et al. 2002; Peters et al. 2003). Not only can G9a regulate the pattern of H3K9 methylation, it also functions in some way in regulating DNA methylation at multiple sites (Xin et al. 2003; Feldman et al. 2006). Furthermore, it has been demonstrated in Arabidopsis that loss of DNA methyltransferase activity can result in alteration in H3K9 methylation patterns (Soppe et al. 2002).

The attachment of methyl groups to histone proteins occurs predominantly at specific lysine or arginine residues, and each site requires the enzymatic activity of a specific class of enzymes. Furthermore, methylated lysine residues within histones can serve as a specific binding site for different proteins. For example, HP1 can recognize and bind to di- and trimethylated H3K9 via its chromodomain (Bannister et al. 2001; Lachner et al. 2001). HP1 was first characterized in Drosophila as a nonhistone chromosomal protein that localized to heterochromatin and was required for gene silencing (Eissenberg and Elgin 2000). Both flies and mammals have more than one HP1-like protein, with each having distinct localizations (for review, see Hediger and Gasser 2006). Mammals have three HP1 isoforms: $\mathrm{HP} 1 \alpha, \mathrm{HP} 1 \beta$, and $\mathrm{HP} 1 \gamma . \mathrm{HP} 1 \alpha$ localizes primarily to pericentric heterochromatin, HP1 $\beta$ localizes primarily to promoters of silent euchromatic genes, and $\mathrm{HP} 1 \gamma$ localizes primarily to coding regions of transcribed genes (Hediger and Gasser 2006). The basis for this localization is unknown, but in Drosophila it appears to depend, in part, on the hinge region and chromo shadow domain of each protein (Smothers and Henikoff 2001). Diversification of function of different HP1s could explain the recent finding of Blobel and colleagues (Vakoc et al. 2005) that H3K9 methylation is found in the coding regions of actively 
transcribed genes. Given this observation, H3K9 methylation is interpreted differently based on the context that it is found (see Eissenberg and Shilatifard 2006 for discussion). Therefore, one needs to go beyond correlating particular modifications with transcriptional states and begin to understand the mechanisms involved in activation and repression of genes, while accounting for the multiple chromatin-modifying complexes present at individual genes. In this issue of Genes \& Development, Smallwood et al. (2007) investigate mechanistic details of transcriptional silencing by histone and DNA methylation and find that the concerted action of histone methyltransferases, HP1 proteins, and DNA methyltransferases are required for this process.

\section{HP1 family members interact with DNA methyltransferases in vitro}

Earlier studies by Kouzarides and colleagues (Fuks et al. 2003 ) indicated that HP1 $\beta$ interacts with DNA methyltransferases, providing the initial direct link between histone and DNA methylation. Smallwood et al. (2007) demonstrate that $\mathrm{HP} 1 \alpha, \mathrm{HP} 1 \beta$, and $\mathrm{HP} 1 \gamma$ all interact with the DNA methyltransferases DNMT1, DNMT3a, and DNMT3b, extending Kouzarides' observations (Fuks et al. 2003) that HP1 $\beta$ interacts with these enzymes. They go on to show that each of the HP1s stimulates the methyltransferase activity of DNMT1, but not DNMT3a or DNMT3b, on DNA templates in vitro, suggesting that the interaction between HP1 and DNMT1 could have a meaningful cellular function. Earlier studies had suggested that H3K9 methylation was upstream of DNA methylation based on the observation that depletion of H3K9 methyltransferases leads to defects in DNA methylation (Tamaru et al. 2003). If K9 methylation recruits HP1 and HP1 recruits a DNA methyltransferase and stimulates its activity, then this would fit with the earlier observations.

Indeed, Smallwood et al. (2007) report that DNMT1 stabilizes HP1 on DNA, suggesting that not only does HP1 recruit DNMT1 to methylated K9 chromatin, but also that DNMT1 then stabilizes HP1 at these sites in a positive feedback loop. It had been previously demonstrated that the K9 methyltransferase G9a increased DNMT1 recruitment, and that DNMT1 stimulated the activity of G9a (Esteve et al. 2006). Furthermore, Smallwood et al. (2007) show that HP1 stimulation of DNMT1 activity is three to four times greater on methylated than unmethylated chromatin. Therefore, they propose a mechanism whereby G9a methylates K9 of H3, a mark that is subsequently bound by HP1. HP1 and G9a both recruit DNMT1 through protein-protein interactions, while HP1 stimulates DNMT1 activity and DNMT1 stabilizes HP1 to ensure stable silencing.

\section{Functional interaction between HP1 proteins and DNMT1 in vivo}

To test for functional interaction between HP1 and DNMT1 in vivo, Smallwood et al. (2007) tethered each of the three HP1s to Gal4's DNA-binding domain and cotransfected each HP1 into cells bearing a Gal4-responsive luciferase reporter plasmid. All three HP1 family members repressed luciferase activity eightfold to 12fold. However, the ability of the HP1s to repress transcription was dramatically reduced in an isogenic cell line in which DNMT1 had been knocked out. Smallwood et al. (2007) used antibodies recognizing methylated cytosine to immunoprecipitate the luciferase reporter plasmids and found that the plasmids were only methylated in the presence of both HP1 and DNMT1, indicating that DNA methylation is very likely to be responsible for the enhanced repression of the luciferase gene.

To determine functional and molecular interactions between H3K9 methylation, HP1, and DNMT1 on an endogenous gene, Smallwood et al. (2007) chose the survivin gene. survivin gene is an anti-apoptotic gene that is repressed by p53 in response to DNA damage. Using the DNA damaging reagent doxorubicin to activate the p53 response, they observe repression of survivin. Chromatin immunoprecipitation was employed to establish that doxorubicin treatment results in the recruitment of p53, DNMT1, G9a, H3K9 methylation, HP1 $\alpha$ and HP1 $\beta$ to the survivin promoter. Interestingly, $\mathrm{HP} 1 \gamma$ was only found at the promoter in the absence of doxorubicin, and disappears upon repression. This suggests that while HP1 $\gamma$ is capable of binding H3K9 methylation as well as DNMT1, other cellular factors are determining its chromosomal distribution. Smallwood et al. (2007) also demonstrated that in the DNMT1 knockout cells, p53 was still efficiently recruited to the survivin promoter in response to DNA damage, but G9a, H3K9 methylation, and HP1 $\beta$ were not. In these cells, HP1 $\gamma$ remained at the survivin promoter before and after DNA damage, consistent with previous results correlating HP1 $\gamma$ association with actively transcribed genes (Vakoc et al. 2005).

\section{Synergism between methylation marks on DNA and histones}

Previous work has suggested that DNA and histone methylation are coordinately regulated. Knocking out DNA methyltransferases has led to altered K9 methylation (Espada et al. 2004), while loss of G9a has resulted in loss of DNA methylation (Ikegami et al. 2007). The work presented by Smallwood et al. (2007) begins to address the mechanism behind this observation both in vitro and in vivo. They propose that the interdependency of the machinery of the two different methylation patterns increases the fidelity of the whole process.

\section{What about flies?}

Drosophila melanogaster noticeably lacks DNA methylation and the DNA methylation machinery required for such modification (for review, see Goll and Bestor 2005). Only small amounts of methylated cytosine can be detected, and is only present at a developmentally restricted window (Lyko et al. 2000). Flies lack DNMT1 and DNMT3 orthologs and the only protein related to methylated DNA-binding proteins lacks conservation 
within the DNA-binding region (Ballestar et al. 2001). Therefore, it is unlikely that DNA methylation plays any significant role in transcriptional silencing in flies. The honey bee has two DNMT1 orthologs but the methylation is primarily in coding regions that contain low densities of CpG dinucleotides, making it unlikely that DNA methylation is involved in gene silencing in this organism either (Wang et al. 2006). How can flies make it through development with only histone methylation while mammals require both DNA and histone methylations? Smallwood et al. (2007) propose that the allosterism between histone and DNA methylation systems increases the fidelity of silencing decisions. Flies could utilize other factors to cooperate with histone methyltransferases and HP1, thereby functionally replacing DNA methylation machinery (Eskeland et al. 2007).

Flies have homologs of the NuRD complex (Ballestar et al. 2001) that in mammals contains methyl CpG-binding proteins, histone deacetylases, and the Mi-2 nucleosome remodeling protein. Rather than being recruited by binding methylated DNA, Drosophila NuRD could be recruited by sequence-specific transcription factors (Kehle et al. 1998, Murawsky et al. 2001). Figure 1 illustrates a model for the similar, but distinct mode of HP1mediated repression in flies and mammals. Whereas flies use histone H3 Lys 9 methylation, HP1 binding, and sequence-specific transcription factors to recruit deacetylases, mammals use DNA methylation to recruit NuRD and to corepress with HP1 proteins. Consistent with this model, it has been shown that tethering HP1 to a gene in Drosophila can result in silencing, despite the lack of DNA methylation machinery (Danzer and Wallrath 2004).

\section{Diversity among HP1 family members and regulation of gene expression}

A notable finding by Smallwood et al. (2007) is that HP1 $\gamma$ behaves differently from HP $1 \alpha$ and HP1 $\beta$ on the survivin gene. They observe a correlation of HP1 $\gamma$ presence on the survivin gene with active transcription, while $\mathrm{HP} 1 \alpha$ and
HP1 $\beta$ only associate with the gene upon repression. However, all of the in vitro studies and transient expression studies show that the three HP1s behave almost identically. How can these results be reconciled? One trivial possibility is that the in vitro assays and transient expression studies do not reveal subtle differences in affinity of HP1 $\gamma$ and the other HP1s for DNMT1. Kinetic studies could potentially reveal such differences. A more interesting possibility is that $\mathrm{HP} 1 \gamma$ retains the ability to interact with DNMT1 and repress transcription, yet can also form additional interactions that $\mathrm{HP} 1 \alpha$ and $\mathrm{HP} 1 \beta$ cannot. The HP1s in flies and mammals differ most prominently in the hinge region, a region important for subcellular targeting (Smothers and Henikoff 2001). Each of the hinge regions is highly modifiable, containing sequences reminiscent of the modification cassettes proposed by Fischle et al. (2003).

\section{Future directions}

Although much has been learned about the molecular machinery required for the implementation of both DNA and histone methylations, very little is known about the molecular mechanism and interdependency between these two methylation marks. In this issue of Genes \& Development, however, Smallwood et al. (2007) have taken the very important first steps toward understanding the connections between histone and DNA methylation in a reconstituted system. Their fundamental study is of great value in defining the interdependency between such processes as DNA and histone methylation, how they are involved in development and differentiation, and why their misregulation results in the pathogenesis of cancer and other human diseases. To capitalize on these findings, future investigations in this area should include structural and kinetic characterization of the interactions between DNMTs, HP1s, and G9a. A better understanding of how they interact could help elucidate the regulation of their target genes, as well as gaining insight to the how and why HP1 $\gamma$ localizes to coding regions of transcribed genes.
A

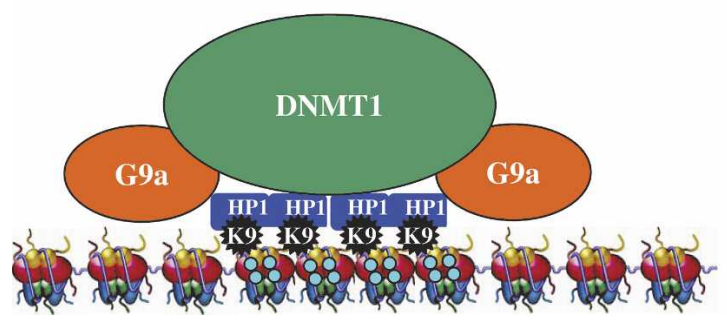

B

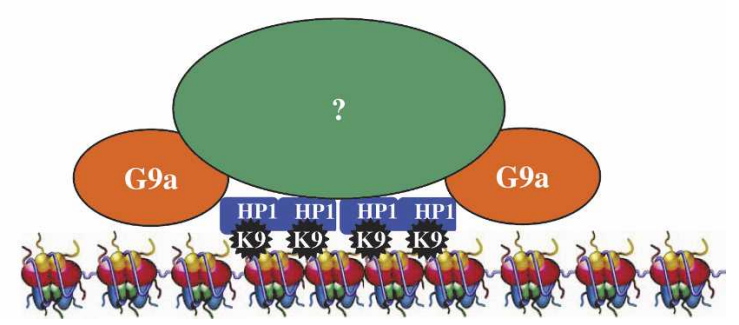

Figure 1. Model for the interactivity between epigenetic modification systems. Smallwood et al. (2007) present evidence for the concerted activity of DNA methylation and histone methylation in the silencing of a euchromatic gene. They propose a model $(A)$ in which HP1 first binds to Lys 9 of H3 (K9) that has been methylated by G9a histone methyltransferase. HP1 interacts with DNMT1 and stimulates its methylation at CpG dinucleotides (blue circles). DNMT1 stabilizes HP1 binding to chromatin and makes further interactions with G9a, providing multiple points of cooperation for gene silencing. $(B)$ In contrast, Drosophila appears to lack DNA methylation, but HP1 and G9a-like histone methyltransferases may be stabilized by other transcription factors, as discussed in the text, to ensure stable silencing of genes. 
Finally, it would be of great interest to determine to what extent the p53-dependent silencing of the survivin gene represents the only mode of HP1-mediated repression in mammals. Chromosome condensation is more complex and more dynamic than previously recognized (Woodcock 2006). Therefore, extending the findings of Smallwood et al. (2007) to further understand the complex interplay among the epigenetic machineries could have profound understanding of development and disease.

\section{References}

Ballestar, E., Pile, L.A., Wassarman, D.A., Wolffe, A.P., and Wade, P.A. 2001. A Drosophila MBD family member is a transcriptional corepressor associated with specific genes. Eur. J. Biochem. 268: 5397-5406.

Bannister, A.J., Zegerman, P., Partridge, J.F., Miska, E.A., Thomas, J.O., Allshire, R.C., and Kouzarides, T. 2001. Selective recognition of methylated lysine 9 on histone $\mathrm{H} 3$ by the HP1 chromo domain. Nature 410: 120-124.

Baylin, S.B. and Jones, P.A. 2007. Epigenetic determinants of cancer. In Epigenetics (eds. C.D. Allis, T. Jenuwein, and D. Reinberg), pp. 457-476. Cold Spring Harbor Laboratory Press, Cold Spring Harbor, NY.

Danzer, J.R. and Wallrath, L.L. 2004. Mechanisms of HP1-mediated gene silencing in Drosophila. Development 131: 3571-3580.

Ebert, A., Lein, S., Schotta, G., and Reuter, G. 2006. Histone modification and the control of heterochromatic gene silencing in Drosophila. Chromosome Res. 14: 377-392.

Eissenberg, J.C. and Elgin, S.C. 2000. The HP1 protein family: Getting a grip on chromatin. Curr. Opin. Genet. Dev. 10: 204-210.

Eissenberg, J.C. and Shilatifard, A. 2006. Leaving a mark: The many footprints of the elongating RNA polymerase II. Curr. Opin. Genet. Dev. 16: 184-190.

Eskeland, R., Eberharter, A., and Imhof, A. 2007. HP1 binding to chromatin methylated at H3K9 is enhanced by auxiliary factors. Mol. Cell. Biol. 27: 453-465.

Espada, J., Ballestar, E., Fraga, M.F., Villar-Garea, A., Juarranz, A., Stockert, J.C., Robertson, K.D., Fuks, F., and Esteller, M. 2004. Human DNA methyltransferase 1 is required for maintenance of the histone H3 modification pattern. J. Biol. Chem. 279: 37175-37184.

Esteve, P.O., Chin, H.G., Smallwood, A., Feehery, G.R., Gangisetty, O., Karpf, A.R., Carey, M.F., and Pradhan, S. 2006. Direct interaction between DNMT1 and G9a coordinates DNA and histone methylation during replication. Genes \& Dev. 20: 3089-3103.

Feldman, N., Gerson, A., Fang, J., Li, E., Zhang, Y., Shinkai, Y., Cedar, H., and Bergman, Y. 2006. G9a-mediated irreversible epigenetic inactivation of Oct-3/4 during early embryogenesis. Nat. Cell Biol. 8: 188-194.

Fischle, W., Wang, Y., and Allis, C.D. 2003. Binary switches and modification cassettes in histone biology and beyond. $\mathrm{Na}$ ture 425: 475-479.

Fuks, F., Hurd, P.J., Deplus, R., and Kouzarides, T. 2003. The DNA methyltransferases associate with HP1 and the SUV39H1 histone methyltransferase. Nucleic Acids Res. 31: 2305-2312.

Goll, M.G. and Bestor, T.H. 2005. Eukaryotic cytosine methyltransferases. Annu. Rev. Biochem. 74: 481-514.

Hediger, F. and Gasser, S.M. 2006. Heterochromatin protein 1: Don't judge the book by its cover! Curr. Opin. Genet. Dev.
16: $143-150$.

Ikegami, K., Iwatani, M., Suzuki, M., Tachibana, M., Shinkai, Y., Tanaka, S., Greally, J.M., Yagi, S., Hattori, N., and Shiota, K. 2007. Genome-wide and locus-specific DNA hypomethylation in G9a deficient mouse embryonic stem cells. Genes Cells 12: 1-11.

Kehle, J., Beuchle, D., Treuheit, S., Christen, B., Kennison, J.A., Bienz, M., and Muller, J. 1998. dMi-2, a hunchback-interacting protein that functions in polycomb repression. Science 282: $1897-1900$.

Lachner, M., O'Carroll, D., Rea, S., Mechtler, K., and Jenuwein, T. 2001. Methylation of histone H3 lysine 9 creates a binding site for HP1 proteins. Nature 410: 116-120.

Li, E. and Bird, A. 2007. DNA methylation in mammals. In Epigenetics (eds. C.D. Allis, T. Jenuwein, and D. Reinberg), pp. 341-356. Cold Spring Harbor Laboratory Press, Cold Spring Harbor, NY.

Lyko, F., Ramsahoye, B.H., and Jaenisch, R. 2000. DNA methylation in Drosophila melanogaster. Nature 408: 538-540.

Murawsky, C.M., Brehm, A., Badenhorst, P., Lowe, N., Becker, P.B., and Travers, A.A. 2001. Tramtrack69 interacts with the dMi-2 subunit of the Drosophila NuRD chromatin remodelling complex. EMBO Rep. 2: 1089-1094.

Peters, A.H., Kubicek, S., Mechtler, K., O'Sullivan, R.J., Derijck, A.A., Perez-Burgos, L., Kohlmaier, A., Opravil, S., Tachibana, M., Shinkai, Y., et al. 2003. Partitioning and plasticity of repressive histone methylation states in mammalian chromatin. Mol. Cell 12: 1577-1589.

Shilatifard, A. 2006. Chromatin modifications by methylation and ubiquitination: Implications in the regulation of gene expression. Annu. Rev. Biochem. 75: 243-269.

Smallwood, A., Estève, P.-O., Pradhan, S., and Carey, M. 2007. Functional cooperation between HP1 and DNMT1 mediates gene silencing. Genes \& Dev. (this issue) doi: 10.1101/ gad. 1536807.

Smothers, J.F. and Henikoff, S. 2001. The hinge and chromo shadow domain impart distinct targeting of HP1-like proteins. Mol. Cell. Biol. 21: 2555-2569.

Soppe, W.J., Jasencakova, Z., Houben, A., Kakutani, T., Meister, A., Huang, M.S., Jacobsen, S.E., Schubert, I., and Fransz, P.F. 2002. DNA methylation controls histone H3 lysine 9 methylation and heterochromatin assembly in Arabidopsis. EMBO J. 21: 6549-6559.

Tachibana, M., Sugimoto, K., Nozaki, M., Ueda, J., Ohta, T., Ohki, M., Fukuda, M., Takeda, N., Niida, H., Kato, H., et al. 2002. G9a histone methyltransferase plays a dominant role in euchromatic histone $\mathrm{H} 3$ lysine 9 methylation and is essential for early embryogenesis. Genes \& Dev. 16: 1779-1791.

Tamaru, H., Zhang, X., McMillen, D., Singh, P.B., Nakayama, J., Grewal, S.I., Allis, C.D., Cheng, X., and Selker, E.U. 2003. Trimethylated lysine 9 of histone $\mathrm{H} 3$ is a mark for DNA methylation in Neurospora crassa. Nat. Genet. 34: 75-79.

Vakoc, C.R., Mandat, S.A., Olenchock, B.A., and Blobel, G.A. 2005. Histone H3 lysine 9 methylation and HP1 $\gamma$ are associated with transcription elongation through mammalian chromatin. Mol. Cell 19: 381-391.

Wang, Y., Jorda, M., Jones, P.L., Maleszka, R., Ling, X., Robertson, H.M., Mizzen, C.A., Peinado, M.A., and Robinson, G.E. 2006. Functional CpG methylation system in a social insect. Science 314: 645-647.

Woodcock, C.L. 2006. Chromatin architecture. Curr. Opin. Struct. Biol. 16: 213-220.

Xin, Z., Tachibana, M., Guggiari, M., Heard, E., Shinkai, Y., and Wagstaff, J. 2003. Role of histone methyltransferase G9a in CpG methylation of the Prader-Willi syndrome imprinting center. J. Biol. Chem. 278: 14996-15000. 


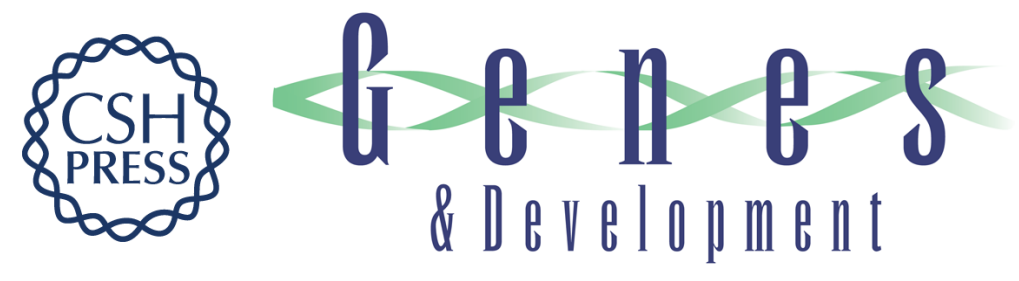

\section{The A, B, Gs of silencing}

Edwin Smith and Ali Shilatifard

Genes Dev. 2007, 21:

Access the most recent version at doi:10.1101/gad.1559407

Related Content Functional cooperation between HP1 and DNMT1 mediates gene silencing Andrea Smallwood, Pierre-Olivier Estève, Sriharsa Pradhan, et al. Genes Dev. May , 2007 21: 1169-1178

References This article cites 30 articles, 12 of which can be accessed free at: http://genesdev.cshlp.org/content/21/10/1141.full.html\#ref-list-1

Articles cited in:

http://genesdev.cshlp.org/content/21/10/1141.full.html\#related-urls

\section{License}

Email Alerting

Receive free email alerts when new articles cite this article - sign up in the box at the top Service right corner of the article or click here.

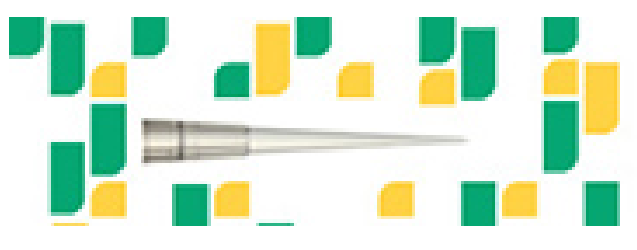

Focused on your science. 